\title{
Financial Data Processing Application On Optical Annisa Blitar
}

\section{Aplikasi Pengolahan Data Keuangan Pada Optik Annisa Blitar}

\author{
Sendi Dwi Jayanti ${ }^{1}$, Sri Lestanti ${ }^{2}$, Ni'ma Kholila ${ }^{3}$ \\ \{ shandyaulya3@gmail.com ${ }^{1}$,Lestanti85@gmail.com², lilaae9@gmail.com ${ }^{3}$ \}
}

Program Studi Teknik Informatika, Fakultas Teknologi Informasi, Universitas Islam Balitar Blitar

\begin{abstract}
Information technology is growing faster, now with the presence of information technology, companies can do business more easily, one of which is the business of optics. Optik Annisa Jaya is one of the companies engaged in the field of glasses in the city of Blitar. Optik Annisa still has several shortcomings, one of which is a mechanism where obstacles in managing financial report data are still carried out by manual processing from recording sales transaction notes and recorded in sales transaction records so that it takes a long time. For making this application using the system development method, namely the method waterfall, a desktop-based application that uses php desktop as the interface design and SQLite as the database. The application testing process uses black box testing using the ISO 9126 standard. Based on the table of results of the assessment of Financial Data Processing Applications at Optik Annisa by media experts, media experts obtained an average feasibility percentage score of (89.5\%) in the "Very Eligible" eligibility criteria with consider some suggestions from experts for future application development to be even better. With the creation of this application, it is hoped that it can help in easy financial management and can handle financial management problems at Optik Annisa.
\end{abstract}

Keywords - Information technology; Waterfall method; PHP Desktop; SQLite; Black Box Testing

\begin{abstract}
Abstrak. Teknologi informasi berkembang semakin cepat, kini dengan hadirnya teknologi informasi, perusahaan dapat melakukan bisnis lebih mudah, salah satunya bisnis tentang Optik. Optik Annisa Jaya merupakan salah satu perusahaan yang bergerak dibidang kacamata yang ada di kota Blitar. Optik Annisa masih memiliki beberapa kekurangan salah satunya adalah mekanisme dimana kendala dalam mengelola data laporan keuangan masih dilakukan dengan cara manual proses dari mendata nota transaksi penjualan dan dibukukan dalam catatan transaksi penjualan sehingga membutuhkan waktu yang lama.Untuk pembuatan aplikasi ini menggunakan metode pengembangan sistem yaitu metode waterfall, aplikasi yang dibuat berbasis desktop dimana menggunakan php desktop sebagai desain interface dan Sqlite sebagai databesnya. Proses pengujian aplikasi menggunakan black box testing menggunakan standart ISO 9126. Berdasarkan tabel hasil penilaian Aplikasi Pengolahan Data Keuangan Pada Optik Annisa oleh ahli media didapat skor persentase kelayakan rata-rata persentase kelayakan yaitu (89,5\%) dalam kriteria kelayakan "Sangat Layak" dengan mempertimbangkan beberapa saran dari para ahli untuk pengembangan aplikasi kedepan agar lebih baik lagi. Dengan adanya pembuatan aplikasi ini diharapkan dapat membantu pengelolaan keuangan yang mudah dan dapat menangani permasalahan pengelolaan keuangan pada Optik Annisa.
\end{abstract}

Kata Kunci - Teknologi informasi; Metode Waterfall; Php Desktop; Sqlite; Black Box Testing

\section{Pendahuluan}

Optik adalah perusahaan yang melakukan usaha dibidang kacamata. Optik Annisa Jaya merupakan salah satu perusahaan yang bergerak dibidang kacamata yang ada di kota Blitar. Mulai beroperasi tahun 2011 sampai sekarang, Optik Annisa Jaya secara resmi telah terdaftar di DEPERINDAG dan DINKES Kota Blitar. Prosedur pelayanan yang diberikan oleh Optik Annisa masih memiliki beberapa kekurangan salah satunya adalah mekanisme dimana kendala dalam mengelola data laporan keuangan masih dilakukan dengan cara manual proses dari mendata nota transaksi penjualan dan dibukukan dalam catatan transaksi penjualan sehingga membutuhkan waktu yang lama.

Kebutuhan sistem pembukuan sangat penting dalam perusahaan, manfaat sistem pembukuan bagi perusahaan antara lain sebagai pendukung dalam pengambilan keputusan untuk mengetahui maju tidaknya perusahaan itu. Berdasarkan uraian yang telah dijelaskan diatas, dimana kendala dalam pengelolaan data dan pembuatan laporan keuangan secara manual, sehingga peneliti menjadikan permasalahan ini sebagai objek penelitian yang berjudul "Aplikasi Pengolahan Data Keuangan Pada Optik Annisa Blitar". Kelebihan dari aplikasi ini berbasis desktop menggunakan php desktop sebagai desain interface dan Sqlite sebagai databesnya, hasil dari pembuatan aplikasi ini diharapkan mampu memberikan kemudahan dalam mengelola laporan dengan cepat dan akurat dan memberikan memudahkan perusahaan dalam mengelola keuangan, maupun pengelolaan data, juga dibuat agar dapat membantu mengurangi resiko kesalahan pada perusahaan. 


\section{Manajemen}

Manajemen adalah proses perencanaan, organisasi, koordinasi, dan kontrol pada sumber daya agar tujuan tercapai secara efektif dan efisien. Efektif di sini maksudnya tujuan tercapai sesuai rencana, dan efisien berarti bahwa manajemen dilakukan secara cermat, terorganisir, dan tepat waktu.

\section{Laporan Keuangan}

Pengertian laporan keuangan adalah laporan yang berisi pencatatan uang dan transaksi yang terjadi dalam bisnis, baik transaksi pembelian maupun penjualan dan transaksi lainnya yang memiliki nilai ekonomi dan moneter. Laporan keuangan dibuat untuk mengetahui kondisi finansial perusahaan secara keseluruhan, sehingga bisa melakukan evaluasi dan cara pencegahan dengan tepat jika kondisi keuangan mengalami masalah.

\section{PHP Desktop}

PHP Desktop adalah open source yang didirikan oleh Czarek Tomczak pada tahun 2012 untuk mengembangkan aplikasi desktop asli menggunakan teknologi web. PHP ini adalah alat yang nyaman untuk mengubah aplikasi web PHP dan alat PHP Cli ke aplikasi desktop dengan sedikit usaha, dalam arti tertentu PHP desktop bertindak sebagai kompiler PHP ke EXE

\section{SQLite}

SQLite itu merupakan sebuah Database yang bersifat ACID-compliant dan memiliki ukuran pustaka kode yang relatif kecil, ditulis dalam bahasa C. SQLite merupakan sebuah open source database yang telah ada cukup lama, cukup stabil, dan sangat terkenal pada perangkat kecil.

\section{Pengujian Black Box}

Metode ini merupakan pengujian terhadap fungsionalitas atau kegunaan sebuah aplikasi.lack box testing adalah pengujian yang dilakukan sepenuhnya dengan hanya menilai kebutuhan dan spesifikasi software. Black box testing cukup meninjau input dan output sistem software tersebut tanpa pengetahuan tentang internal programnya.

\section{METODE}

Dalam pembuatan aplikasi ini saya menggunakan metode waterfall yang merupakan pendekatan SDLC paling awal yang digunakan untuk pengembangan perangkat lunak. Urutan dalam Metode Waterfall bersifat serial yang dimulai dari proses perencanaan, analisa, desain, dan implementasi pada sistem.

Instrumen penelitian merupakan alat yang digunakan untuk memperoleh dan mengumpulkan data dibutuhkan dalam penelitian. Pengumpulan data adalah langkah utama dalam penelitian. Data bisa memiliki banyak jenis mulai dari suara, angka, huruf, gambar, simbol.

Jenis data yang digunakan primer dan sekunder. Pada penelitian ini jawaban data primer didapat dari wawancara. Data sekunder berupa bukti, catatan atau laporan (data dokumenter). Data sekunder didapat dari rekap data pengelolaan pembukuan di Optik Annisa Blitar.

\section{Hasil dan Pembahasan}

\section{Hasil Implementasi}

Hasil implementasi Aplikasi Pengolahan Data Keuangan Pada Optik Annisa Blitar terdiri dari beberapa tahap antara lain sebagai berikut:

\section{Tampilan Login}

Tampilan login merupakan tampilan pertama saat aplikasi dijalankan. Login adalah suatu proses untuk masuk ke dalam sebuah layanan yang berisi nama dan password diinputkan. 
Procedia of Enginering and Life Science Vol. 2. No. 1 Oktober 2021

Seminar Nasional \& Call Paper Fakultas Sains dan Teknologi (SENASAINS 3rd) Universitas Muhammadiyah Sidoarjo

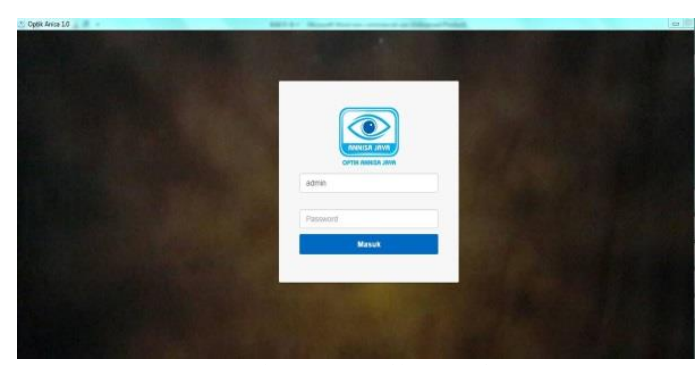

Gambar 1 Tampilan Login

\section{Menu Utama}

Menu utama aplikasi adalah tampilan lanjutan setelah login, Pada tampilan ini pengguna aplikasi dapat mengklik salah satu tombol menu untuk masuk ke menu yang diinginkan.. Dalam menu ini terdapat beberapa pilihan data, transaksi, register, setting user.

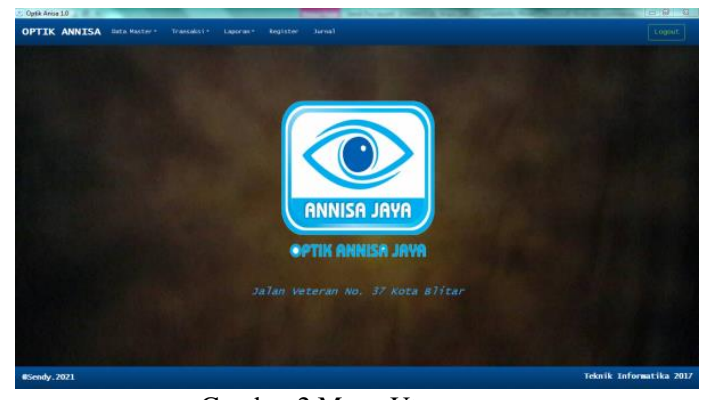

Gambar 2 Menu Utama

\section{Tampilan Menu Register}

Pada menu ini berfungsi untuk pengecekan data customer dan pengecekan transaksi keuangan untuk rincian pembayaran customer. pada menu ini bisa mencari data customer berdasarkan kode yang diinginkan memudahkan pencarian data yang jumlahnya banyak.

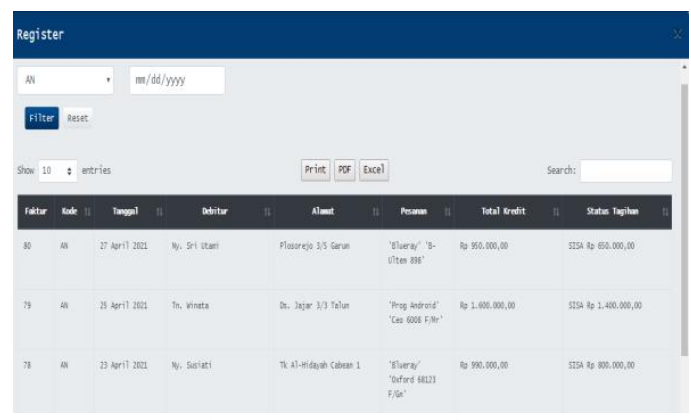

Gambar 3 Form Menu Register

\section{Tampilan Setting}

Merupakan tampilan setting/ ubah data karyawan termasuk mengubah username dan password. 
Procedia of Enginering and Life Science Vol. 2. No. 1 Oktober 2021

Seminar Nasional \& Call Paper Fakultas Sains dan Teknologi (SENASAINS 3rd) Universitas Muhammadiyah Sidoarjo

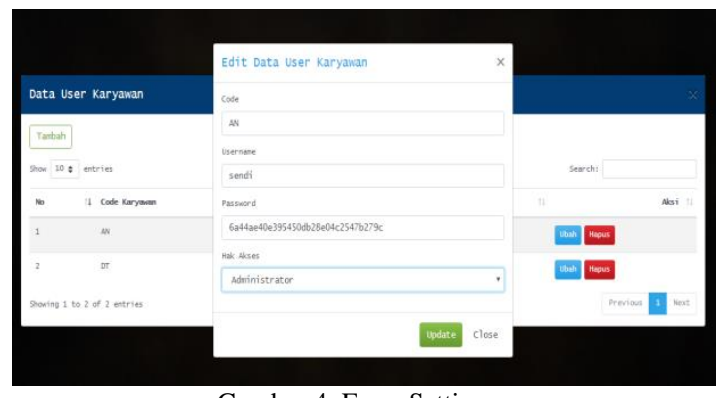

Gambar 4 Form Setting

\section{Hasil Implementasi Pengujian}

Pengujian ini dilakukan dengan menguji proses mencari kesalahan yang terjadi untuk setiap proses. Pada pengujian ini ditentukan terlebih dahulu yang akan diujikan dan hasil yang diharapkan ketika aplikasi dijalankan, mulai dari awal login, input data, mengubah data, menghapus data, Pengujian Setting Username/ Password.

Setelah melakukan pengujian langkah selanjutnya untuk menghitung tingkat akurasi dari pengujian Black box sebagai berikut :

$\mathrm{X}=\frac{\text { Jumlah Berhasil }}{N \text { Pengujian }} \times 100 \%$

\section{Keterangan :}

$\mathrm{X}=$ Akurasi Pengujian

Jumlah Berhasil = Jumlah hasil pengujian yang berhasil

$\mathrm{N}$ pengujian $=$ Banyak data Pengujian

\section{Pengujian Login}

\begin{tabular}{|c|c|c|c|c|}
\hline No & $\begin{array}{c}\text { Hal Yang } \\
\text { Dilakukan }\end{array}$ & Pengujian & $\begin{array}{c}\text { Kondisi Yang } \\
\text { Diinginkan }\end{array}$ & $\begin{array}{c}\text { Hasil } \\
\text { Pengujian }\end{array}$ \\
\hline 1. & Klik tombol masuk & $\begin{array}{l}\text { Usemame dan Password } \\
\text { tidak diisi kemudian klik } \\
\text { tombol Masuk }\end{array}$ & $\begin{array}{l}\text { Sistem menolak dan } \\
\text { kursor tetap berada di } \\
\text { Usemame }\end{array}$ & Berhasil \\
\hline 2. & Klik tombol masuk & $\begin{array}{l}\text { Usemame dan Password } \\
\text { diisi salah kemudian klik } \\
\text { tombol Masuk }\end{array}$ & $\begin{array}{l}\text { Sistem menolak dan } \\
\text { menampilkan pesan } \\
\text { "Gagal login, usemame } \\
\text { dan password salah" }\end{array}$ & Berhasil \\
\hline 3. & Klik tombol masuk & \begin{tabular}{l}
\multicolumn{3}{l}{ Usemame dan Password } \\
diisi dengan benar \\
kemudian klik tombol \\
Masuk
\end{tabular} & $\begin{array}{l}\text { Sistem menerima akses } \\
\text { login dan kemudian } \\
\text { menampilkan halaman } \\
\text { utama }\end{array}$ & Berhasil \\
\hline
\end{tabular}

Gambar 5 Pengujian Login

Hasil pengujian akurasi yang telah dihitung :

$\mathrm{X}=\frac{3}{3} X 100 \%$

$X=100 \%$ 
Procedia of Enginering and Life Science Vol. 2. No. 1 Oktober 2021

Seminar Nasional \& Call Paper Fakultas Sains dan Teknologi (SENASAINS 3rd) Universitas Muhammadiyah Sidoarjo

\section{Pengujian Input Data}

\begin{tabular}{|c|c|c|c|c|}
\hline No & $\begin{array}{c}\text { Hal Yang } \\
\text { Dilakukan }\end{array}$ & \multicolumn{1}{|c|}{ Pengujian } & \multicolumn{1}{|c|}{$\begin{array}{c}\text { Kondisi Yang } \\
\text { Diinginkan }\end{array}$} & $\begin{array}{c}\text { Hasil } \\
\text { Pengujian }\end{array}$ \\
\hline 1. & $\begin{array}{c}\text { Klik tombol } \\
\text { tambah }\end{array}$ & $\begin{array}{l}\text { Menyimpan data sesuai } \\
\text { denganyang dinput } \\
\text { mulai dari pesanan } \\
\text { kacamata sampai } \\
\text { transaksi pembayaran }\end{array}$ & $\begin{array}{l}\text { Sistem berjalan dan data } \\
\text { yang disimpan masih } \\
\text { dapat diubah }\end{array}$ & Berhasil \\
\hline 2. & $\begin{array}{l}\text { Klik tombol } \\
\text { tambah }\end{array}$ & $\begin{array}{l}\text { Pengisian data tidak } \\
\text { lengkap }\end{array}$ & $\begin{array}{l}\text { Data yang diinputkan } \\
\text { sesuai dan bisa diubah }\end{array}$ & $\begin{array}{c}\text { Tidak } \\
\text { Berhasil }\end{array}$ \\
\hline
\end{tabular}

Gambar 6 Pengujian Input Data

Hasil pengujian akurasi yang telah dihitung :

$\mathrm{X}=\frac{1}{2} X 100 \%$

$X=50 \%$

\section{Pengujian Ubah Data}

\begin{tabular}{|c|c|c|c|c|}
\hline No & $\begin{array}{c}\text { Hal Yang } \\
\text { Dilakukan }\end{array}$ & \multicolumn{1}{|c|}{ Pengujian } & \multicolumn{1}{|c|}{$\begin{array}{c}\text { Kondisi Yang } \\
\text { Diinginkan }\end{array}$} & $\begin{array}{c}\text { Hasil } \\
\text { Pengujian }\end{array}$ \\
\hline 1. & Klik tombolubah & $\begin{array}{l}\text { Menginput data baru dan } \\
\text { mengubah datalama }\end{array}$ & $\begin{array}{l}\text { Sistem berjalan dan data } \\
\text { yang disimpan masih } \\
\text { dapat diubah }\end{array}$ & Berhasil \\
\hline 2. & Klik tombolubah & $\begin{array}{l}\text { Menginput data baru } \\
\text { dibagian transaksi dan } \\
\text { mengubah data dibagian } \\
\text { nominaluang }\end{array}$ & $\begin{array}{l}\text { Sistem berjalan dan data } \\
\text { yang disimpan masih } \\
\text { dapat diubah }\end{array}$ & $\begin{array}{c}\text { Tidak } \\
\text { Berhasil }\end{array}$ \\
\hline & Gambar 7 Pengujian Ubah Data & \\
\hline
\end{tabular}

Hasil pengujian akurasi yang telah dihitung :

$X=\frac{1}{2} X 100 \%$

$\mathrm{X}=50 \%$

\section{Pengujian Hapus Data}

\begin{tabular}{|c|c|c|c|c|}
\hline No & $\begin{array}{l}\text { Hal Yang } \\
\text { Dilakukan }\end{array}$ & Pengujian & $\begin{array}{c}\text { Kondisi Yang } \\
\text { Diinginkan }\end{array}$ & $\begin{array}{c}\text { Hasil } \\
\text { Pengujian }\end{array}$ \\
\hline 1. & Klik tombol hapus & $\begin{array}{l}\text { Muncul peringatan } \\
\text { "yakin ingin } \\
\text { menghapus"klik okjika } \\
\text { ingin menghapus, atau } \\
\text { klik cancel jika ingin } \\
\text { membatalkan }\end{array}$ & $\begin{array}{l}\text { Sistem berjalan dan data } \\
\text { terhapus permanen }\end{array}$ & Berhasil \\
\hline
\end{tabular}

Gambar 8 Pengujian Hapus Data

Hasil pengujian akurasi yang telah dihitung :

$X=\frac{1}{1} X 100 \%$

$\mathrm{X}=100 \%$ 
Procedia of Enginering and Life Science Vol. 2. No. 1 Oktober 2021

Seminar Nasional \& Call Paper Fakultas Sains dan Teknologi (SENASAINS 3rd) Universitas Muhammadiyah Sidoarjo

\section{Pengujian Setting Username/ Password}

\begin{tabular}{|c|c|c|c|c|}
\hline No & $\begin{array}{l}\text { Hal Yang } \\
\text { Dilakukan }\end{array}$ & Pengujian & $\begin{array}{c}\text { Kondisi Yang } \\
\text { Diinginkan }\end{array}$ & $\begin{array}{c}\text { Hasil } \\
\text { Pengujian }\end{array}$ \\
\hline 1. & $\begin{array}{l}\text { Klik menu data } \\
\text { master }\end{array}$ & $\begin{array}{l}\text { Masuk data user } \\
\text { karyawan, klik tombol } \\
\text { ubah disalah satukode } \\
\text { yangingin diubah, isi } \\
\text { usemame dan password } \\
\text { yang barulalu klik } \\
\text { tombolupdate }\end{array}$ & $\begin{array}{l}\text { Sistem berjalan, update } \\
\text { usemame dan password } \\
\text { yang baru telah diubah }\end{array}$ & Berhasil \\
\hline
\end{tabular}

Gambar 9 Pengujian Setting

Hasil pengujian akurasi yang telah dihitung :

$\mathrm{X}=\frac{1}{1} X 100 \%$

$X=100 \%$

Hasil persentase akurasi yang sudah dihitung nilai rata-rata dengan menggunakan rumus sebagai berikut

Presentase Kelayakan $(\%)=\frac{400}{500} \times 100 \%$
$=75 \%$

Dari Pengujian Black Box testing tersebut yang telah dilakukan, diperoleh tingkat akurasi $80 \%$ dapat disimpulkan bahwa aplikasi yang dibangun sudah layak digunakan dan memenuhi persyaratan fungsionalnya, akan tetapi tidak menutup kemungkinan pada proses masih terjadi kesalahan. Secara fungsional sistem yang dibuat sudah menghasilkan keluaran yang diharapkan.

\section{KESIMPULAN}

Berdasarkan pembahasan yang telah dikemukakan sebelumnya, maka kesimpulan yang diambil dari penilitian ini adalah :

1. Berbagai kemudahan aplikasi dapat dilihat dari pengguna/ user untuk mengakses setiap fitur yang ada. Selain mudah digunakan aplikasi ini juga mudah dipahami dan efektif membantu menyelesaikan permasalahan data laporan keuangan lebih baik. Dengan adanya aplikasi keuangan ini perusahaan menjadi lebih praktis dan mudah dalam menambahkan data keuangan setiap harinya lalu pencarian data keuangan juga lebih cepat karena bisa langsung dicari berdasarkan kategori.

2. Pada proses pengujian telah dilakukan, diperoleh tingkat akurasi $80 \%$ artinya aplikasi berhasil berjalan dengan baik sesuai yang diharapkan. Hasil pengujian mendapatkan nilai tersebut dipengaruhi oleh beberapa skenario pengujian seperti : login, input data, ubah data, hapus data, dan setting username/ password dapat disimpulkan bahwa aplikasi yang dibangun sudah layak digunakan dan memenuhi persyaratan fungsionalnya. 


\section{REFERENSI}

[1] Alkadrie, S. A., \& Wahyudi, F. A. (2020). Analisis Promotion Mix Dalam Meningkatkan Volume Penjualan Produk Kacamata Toko Optik Nasional Tanjung Hulu Pontianak Timur. JES (Jurnal Ekonomi STIEP), 5(1), 56-63.

[2] Bello, R. O., Olugbebi, M., BABATUnde, A. O., BELlO, B. O., \& BELlO, S. I. (2017). A University Examination Web Application Based on Linear-Sequential Life Cycle Model.

[3] Dharmawan, W. S., Purwaningtias, D., \& Risdiansyah, D. (2018). Penerapan metode SDLC waterfall dalam perancangan sistem informasi administrasi keuangan berbasis desktop. Jurnal Khatulistiwa Informatika, 6(2).

[4] Fikri, N., Rida, M., Abghour, N., Moussaid, K., \& El Omri, A. (2019). An adaptive and real-time based architecture for financial data integration. Journal of Big Data, 6(1), 1-25.

[5] Mashud, M., \& Herni, H. (2018). Aplikasi Analisis Laporan Keuangan Dengan Metode Analisis Rasio Keuangan Berbasis Web Pada PT. Sinar Galesong.

[6] Safitri, N., \& Pramudita, R. (2018). Pengujian Black Box Menggunakan Metode Cause Effect Relationship Testing. INFORMATION SYSTEM FOR EDUCATORS AND PROFESSIONALS: Journal of Information System, 3(1).

[7] Rahayu, S., Sari, A. R., \& Saputra, T. S. (2018). Analisa sistem informasi pengelolaan keuangan pada upt dinas pendidikan kecamatan neglasari kota tangerang. Journal Sensi, 4(1). 